\title{
Nurturing Medical Professionalism in the Surgical Community
}

\author{
Daniel Kinyuru Ojuka ${ }^{1}$, Joyce Olenja ${ }^{2}$, Eunbae Yang $^{3}$, Nimrod Juniahs Mwangombe ${ }^{1}$, Jana Macleod ${ }^{4}$ \\ 1.School of Medicine, University of Nairobi \\ 2.School of Public Health,University of Nairobi \\ 3.Department of Medical Education, Yonsei University, Seoul , South Korea \\ 4.School of Medicine, Kenyatta University
}

Correspondence to: Dr. Daniel Ojuka, P.0 Box 20723-00202, KNH, Nairobi. Kenya. Email: danielojuka@gmail.com

\begin{abstract}
Introduction: The teaching of professionalism worldwide is changing for effectiveness. Our aim was to explore the reflection of the surgical teaching community in a Kenyan context on how professionalism can be effectively inculcated through the socio-cultural concept of activity theory. Methods: A sequential mixed-methods study was conducted among clinicians and students within the surgical community of the University of Nairobi from March to December 2014. . Individual interviews and focusgroup-discussions were conducted using grounded theory methods. A survey of the resultant views was performed through a pre-determined questionnaire which utilized a 4-point Likert scale for response ranging from "strongly agree" to "strongly disagree". Factor analysis was used to analyze the responses to the survey. Internal reliability was determined by Cronbach's $\alpha$. Results: Four themes emerged from the interviews; change of values, regulation, enabling
\end{abstract}

\section{Introduction}

The teaching of values requires congruency in what is being taught and what is being demonstrated (1). 'Lack of such congruency is a hindrance to the socialization process that is the current norm in teaching of professionalism (2). Further, the tendency in medical school to major on teaching objective sciences gives little room for professionalism as a subject worth teaching and examining (3). A number of methods of teaching professionalism have been suggested, implying there is no one agreeable way, and that any method will be encumbered by challenges in various contexts. environment and formal curriculum. In the survey, the participants strongly agreed with strengthening mentorship (77.5\%) and a teaching facility (74.7\%) with a rewarding or recognition (69.5\%). The reliability test of the items showed a Cronbach's $\alpha$ of 0.827. Conclusion: This study demonstrates that the participants would like to see a different and transforming path in inculcating professionalism through changing values and enabling environment among others.

Key words: Nurturing, Medical professionalism, Surgical community

Ann Afr Surg. 2017;14(2):10-18.

DOI: https://dx.doi.org/10.4314/aas.v14i1.3

(C) 2017 Annals of African Surgery. This work is licensed under the Creative Commons Attribution 4.0 International License.

Our context is faced with three-fold challenges of lack of resources, incongruence in morals to what is taught, lack of clear formal curriculum and therefore the teaching of professionalism is left to the informal and hidden curriculum (4). Furthermore, the behavior of doctors has come into sharp focus in the public domain through the print media $(5,6)$. Such negative publicity may bring about cognitive dissonance as was described by Festinger, but through the community reflecting on this activity it is possible that they themselves can suggest transformative changes as was suggested by Daryl Bem in his self-perception theory $(7,8)$. Self-perception allows for professionals 
to look at their current behaviors and change their attitudes through critical thinking. This is further buttressed by the Mezirow's theory of transformative learning, especially the communicative process where there is questioning of goals, values and norms of the community through the critical thinking process (9). We therefore believe that by these two critical learning theories and the methodology using Activity Theory, we could arrive at the reflections of the participants that would shape how professionalism can be effectively taught (10).

\section{Methods}

The study was conducted within the department of surgery at the University of Nairobi (UoN) and the surgical wards at Kenyatta National Hospital (KNH). The study population included consultants and surgical residents..

We used a sequential mixed method comprising qualitative and quantitative surveys among the surgical teaching community. The framework we based our methodology on was the Activity Theory (AT) which takes the learning environment as a single unit of analysis. This is because the process of thinking through what should be in the curriculum is beyond just the learner or the faculty, it embraces the sociocultural context. AT conceptualizes learning as a transformation and identity formation process for the student.

Ethical approval to conduct this study was obtained from the KNH-UoN Ethics and Research Committee (Reference Number P59/11/2013).

We used purposive sampling in the qualitative study for the focus group discussion of 10-12 participants and the key informant interviews. We held keyinformant interview with senior faculty who had been in the department for more than 20 years while with the rest we had focus group discussion. We used grounded theory methods of data collection and analysis for both the focus group discussion and the key informant interview.

The guiding question for clinicians was, "Could you describe how we can effectively teach professionalism given the challenges in our environment?" The data were collected mainly by tape recording using a Sony ICD BX112 2GB during the interviews. The principal investigator facilitated the interviews while an assistant recorded the events. The records were transcribed and entered into Atlas 5.2 .0 by an assistant who had 5 years of experience in qualitative research. The collection of data through the interviews was conducted in tandem with analysis until saturation was deemed to have been reached, which was determined by the repetition of ideas already mentioned in other groups. After saturation, we codified the themes and domains that emerged from the interviews and piloted a questionnaire among five faculty members. This process led to the revision of the questionnaire, which was then distributed to similar participants. The survey question was, "The items below describe how challenges in the practice and teaching of professionalism can be overcome in University of Nairobi." The responses provided in the survey were analyzed on a 4-point Likert scale rated strongly agree (4), agree (3), disagree (2), and strongly disagree (1) (see Appendix)

Descriptive statistics were used to analyze responses from thesurvey to identify measures of central tendency for each main domain. Factor analysis with promax rotation and Kaiser-Meyer-Olkin normalization was used to explore the structure underlying the 16 items reflective of methods for the better inculcation of professionalism in the training of medical students and postgraduates. The Kaiser criterion was used to drop the least important factors from the analysis when Eigen values were <1.0. Internal consistency reliability was determined by employing Cronbach's $\alpha$.

\section{Results}

We analyzed 26 interviews consisting of 16 focus group discussion and ten key informant interviews with senior faculty. The focus group discussion and individual interview generated about 16 concepts that participants felt were ways of overcoming the challenges and effectively teach professionalism to the medical students and postgraduates.

On further thematic analysis, four themes emerged as shown in Table 1.

The themes are discussed below and illustrated by the excerpts from the interviews.

\section{Overcoming the challenge of personal character to foster professionalism}

While self-regulation is part of professionalism, it seems that it begins after graduation. However in medical school and even among postgraduates there appears to be problems that require the regulatory body. It was suggested that this regulation should begin from medical school, and should be systemic 
so as to enable individuals to form their identity from early on.

"This regulatory authority which you say should be the last stage, I think that is a big mistake; some of us [are] not [aware] that [regulatory] body exists until you become a doctor. I think the board should come in right from the first year, let whoever is coming in get to know what it means to be in this profession, the regulations, the punishments so that they grow with it, as they come out they know what is expected regarding discipline." FGD F-2

Role-modeling requires congruency of the rhetoric with the lifestyle of the instructor. The participants suggested that mentorship in small groups would enable critical thinking and questioning of values practiced, therefore ensuring there is transformation at the individual level through the group.

"Mentorship Programs also really help. If every registrar is attached to a fifth year and to a fourth year, it's a sort of a linking chain where you actually take responsibility to people near your level" FGDM-2

Peer mentorship through benchmarking by the way of exchange program with other universities was another way that was suggested to boost the inculcation of professionalism

"Alternatively, I think we can have like exchange programs with the other institutions, or like other medical schools so that we can see like how they do it. What we consider as being professional may not be regarded as professional elsewhere, so through those programs we can learn a lot." FGD F-1

\section{Overcoming the challenge of institutional inadequacies to foster professionalism}

Institutions need to have cultures that enable professionalism and part of the challenges as we have seen is institutional issues that are proxy for institutional cultures that may not enable professionalism. Cultural change requires leadership. We require leadership to modify the ideals of the institution at the entry of teachers and students. The recruitment of medical educators and students should not only be on grades but on the idea that medicine is a calling that requires passion and commitment without ignoring academic abilities.

"I agree that some things need to change and it will take the leadership to create awareness and bring in the new ideas" FGDM-1

"Medicine is not really about the grade; it comes with a passion. Do you have a passion for patients? The vocation aspect plays a role. If it's something you really want to do, then you'll be comfortable doing it other than doing something because you think there's money". FGDM-5

The participants also shared the idea that the wards and operation room are not adequate, there is need to have people work in shift to decongest the wards. There were also suggestions this could be advanced to managing the institution in small manageable areas so that the work is done more efficiently. The other suggestion was better remuneration for retention of doctors within the country.

"The numbers of patients in the ward waiting for surgery in some wards are high, with high number of surgeries being postponed. Instead of ten surgeries they'll do five. The service provider should work in shifts like in theatre; the work should not only be done during the day. A half of them should come during the day, the other during night and if that would happen we would not have these backlogs we have in the wards" FGDR-1

The environment can be made enabling by better management of resources so that we can deliver on our mandate. If that is not possible because of twin administrative structures, maybe the best would be to get a university hospital for wholesome teaching with one administration.

"Looking at it from an institutional point of view, we need to decide that we are actually going to teach the students the right thing. I think our problem is that we are linked to a government hospital which is to some extent being mismanaged such that we keep getting the wrong picture of how a hospital runs. Either we would transform the way the hospital is run, or we get our teaching hospital". FGDF-2

There is a need for a better reward system for motivation purposes for change and the continued practice of professionalism.

"Having some form of reward system where someone is appreciated. You work the whole night and nobody sees the good in what you do; some level of recognition can motivate you" FGDR-1

\section{Fostering professionalism through having shared values}

Teaching for a deeper understanding that would change character requires integrating cultural constructs. In a more collectivistic than individualistic style, reducing the power distance between teacher and student helps in enhancing understanding of what it means to be professional. This understanding can be better when it is begun earlier.

"A career day where they bring different professionals: pilot, a doctor, an engineer and each speaks about the career, the positives, and the negatives, then they tell you, you have to decide. So, that people do not go into any career because of financial issues, one should be told what's important for you to go to any career is your passion. So, I think it should start early before one gets frustrated". FGD F-1 
An informal setting where people talk without fear of victimization helps to set up an environment of knowing people better. It is only in doing this that characters of colleagues will be known, and collegiality developed between juniors and seniors and between peers. This then enables correction of bad attitudes and character without seeming to be malicious to anyone.

"We must deliberately develop the social networks so that when I see this colleague of mine seems to have issues, we must find a way of bringing him back, and you see that will also help us to do what we call selfregulation within the profession". FGD F-2

\section{Overcoming inadequate capacity and lack of curriculum}

Learning abstract values requires a lecturer who understands and demonstrates issues so that the students grasp them in their cognitive domain to enable them to practice them.

"They should be like classes on bedside manners, defining professionalism in theoretical classes, so that when [one] knows what they are supposed to do. When [they] go for practical lessons, then [they] are shown what [they] already have in theory" FGDM-7 Furthermore, in a field such as professionalism, there needs to be faculty training so that there is understanding of the issues by the teachers that will help them teach and assess; this could take the form of workshops and retreats.
"Train the teachers well and explain to them the importance of professionalism. An institutional framework whereby, for some periodic retreats, so that whereby the doctors go and assess themselves and do team building." KIF-2

Given the large numbers of students and increased workload, it was suggested that there is a need to increase the teaching staff to student ratio for a better apprenticeship to take place.

"For training purposes, the number should be reduced, or the staff increased so that when you are having bedside teaching you have 2 to 3 students; each gets to do the full procedure like to examine the abdomen". FGDM-5

Results of the survey on the views about how to effectively teach professionalism

In the survey, some of the nuances of the concepts were taken up, e.g. working in shifts and working in manageable units and some were combined in regulatory aspects making 16 instead of 15 .

The methods that the participants thought were the most important ways of overcoming the challenges in order to effectively foster professionalism included good and improved mentorship programs $(77.5 \%$ strongly agree).Teaching medicine as a calling was one of the ways least seen as a way of fostering professionalism (Table 2).

Table 1: Emerging themes and the constituent concepts of ways of overcoming the challenges and effectively teaching professionalism at the University of Nairobi

\begin{tabular}{|l|l|}
\hline Themes & Concepts \\
\hline $\begin{array}{l}\text { Overcoming issues of personal } \\
\text { character }\end{array}$ & $\begin{array}{l}\text { Strengthening regulation } \\
\text { Strengthening mentorship program } \\
\text { Leadership for change } \\
\text { Professional bodies having a role in regulating the profession }\end{array}$ \\
\hline Overcoming institutional problem & $\begin{array}{l}\text { Having a separate teaching facility for the University } \\
\text { Social networks } \\
\text { Better management of resources } \\
\text { Increasing the number of teachers } \\
\text { Reward system } \\
\text { Better remuneration } \\
\text { Work Shifts }\end{array}$ \\
\hline Overcoming inadequate capacity & $\begin{array}{l}\text { Faculty development } \\
\text { Formal training } \\
\text { Exchange programs to benchmark }\end{array}$ \\
\hline Focus on aptitude & Teaching medicine as a calling \\
\hline
\end{tabular}


Table 2: Frequency table for the items surveyed for nurturing professionalism

\begin{tabular}{|l|l|l|l|l|l|}
\hline & $\mathrm{n}$ & Strongly agree\% & Agree \% & Disagree \% & Strongly disagree \% \\
\hline Mentorship programs & 173 & 77.5 & 20.8 & 1.7 & 0.0 \\
\hline Excellent teaching facility & 174 & 74.7 & 24.7 & 0.6 & 0.0 \\
\hline Reward system & 174 & 69.5 & 29.4 & 1.1 & 0.0 \\
\hline Remuneration & 173 & 67.6 & 29.5 & 2.89 & 0.0 \\
\hline Exchange programs & 172 & 64.5 & 35.5 & 0.0 & 0.0 \\
\hline Regulation & 176 & 58.5 & 38.7 & 2.8 & 0.0 \\
\hline Faculty development & 174 & 59.2 & 38.5 & 2.3 & 0.0 \\
\hline Smaller manageable areas & 174 & 57.4 & 36.8 & 5.2 & 0.6 \\
\hline Leadership & 173 & 56.1 & 41.6 & 2.3 & 0.0 \\
\hline Formal curriculum & 172 & 55.2 & 41.3 & 2.3 & 1.2 \\
\hline Work shifts & 171 & 51.4 & 39.8 & 8.2 & 0.6 \\
\hline Increase number of lecturers & 173 & 50.3 & 36.4 & 11.6 & 1.7 \\
\hline Social program & 172 & 44.2 & 51.7 & 3.5 & 0.6 \\
\hline Recruitment & 172 & 41.3 & 48.8 & 8.7 & 1.2 \\
\hline Getting a teaching site & 174 & 40.2 & 39.1 & 17.8 & 2.9 \\
\hline Medicine as a calling & 173 & 24.9 & 43.9 & 25.4 & 5.8 \\
\hline
\end{tabular}

Table 3: Factor loading, Eigenvalues and percentage variance of the four factors loaded by fifteen items on fostering professionalism

\begin{tabular}{|l|l|l|l|l|}
\hline \multirow{2}{*}{ Item } & \multicolumn{2}{|l|}{ Factors } & Aptitude \\
\cline { 2 - 5 } & $\begin{array}{l}\text { Better teaching } \\
\text { environment }\end{array}$ & $\begin{array}{l}\text { Character } \\
\text { formation }\end{array}$ & $\begin{array}{l}\text { Making work } \\
\text { easier }\end{array}$ & \\
\hline Regulations & & 0.825 & & \\
\hline Leadership & & 0.648 & & \\
\hline Mentorship program & & 0.58 & & \\
\hline Exchange programs & & 0.378 & & 0.546 \\
\hline Recruitment & & & & 0.783 \\
\hline Medicine as a calling & & & & 0.511 \\
\hline Social Program & & & & \\
\hline Formal curriculum & & & 0.805 & \\
\hline Faculty development & & & 0.599 & \\
\hline Work shifts & & & 0.625 & \\
\hline Small manageable areas & & & 0.468 & \\
\hline Excellent teaching facility & 0.782 & & & \\
\hline Increase the number of lecturers & 0.674 & & & \\
\hline Reward system & 0.757 & & & \\
\hline Teaching site & 0.552 & & & \\
\hline Remuneration & 0.517 & & & \\
\hline Eigen value & 4.82 & 1.78 & 1.4 & 5.11 \\
\hline$\%$ variance & 30.12 & 11.17 & 8.72 & \\
\hline Cumulative variance & 30.12 & 41.29 & 50.01 & \\
\hline
\end{tabular}


Exploration of the 15 items to find whether there are 'hidden principles' that could reduce them to organized groups, we performed factors analysis. Kaiser-MeyerOklin Bartlett was 0.924 with a p-value of $<0.001$.The reliability test of the items showed a Cronbach's $\alpha$ of 0.827 . Only four factors had Eigenvalues greater than 1.

Factor analysis resulted in 4 factors which accounted for $57.1 \%$ of the variance, the largest component of which (30.12\%) was accounted for by factor 1 . The loading of items indicated the following factor structure:

Factor1 (Better teaching environment) was loaded with the following items; good teaching facility, increase the number of lecturers, reward system, university teaching site, and better remuneration.

Factor 2 (character formation) with the following items; regulations, leadership, mentorship programs and exchange programs. The loading of exchange program is below 0.5 and therefore not significant in defining the factor.

Factor 3 (Making work easier), had the following items loading; formal curriculum, faculty development, work shifts, and small manageable areas. The loading of small manageable areas is below 0.5 and may not be useful in defining this factor.

Factor 4 (Aptitude) loaded the following items: recruitment, medicine as a calling, and social program (Table 3).

\section{Discussion}

The inadequate learning of professionalism has been demonstrated in the print media bringing into sharp focus the erosion of values among the practitioners of medicine (11).

The values of practitioners in the context have been noted as challenges (4). Therefore, the reflection of the community on this may suggest a transformation of character that begins with a change of values at the institutional level, especially so at the entry point of the teachers and the students. The values must be those of commitment to the professional principles of morality, which views medicine as a 'call' (12).

One of the factors that have been recognized as a major challenge to role modeling is the change in values from one generation to the next (13). However, values not only change across generation but also across cultures. When culture values 'respect' above truth, it may hinder role modeling as a form of teaching professionalism. It is, therefore, fitting in this context, that values that promote professionalism should be encouraged to change at the point of entry, so that socialization can take place with similar values. Changing cultural values requires leadership as suggested in this and other studies (13). Leadership may not have been the most prominent finding but it was mentioned in the interviews and was rated fifth in the survey indicating the recognition of its need in our context.

Lave and Wenger's community of practice theory on how learning takes place in a social context has been a major driver for the third-loop of learning professionalism, its limitation is thought to be the hidden curriculum (14). The hidden curriculum is not always a weakness. When it was first applied to education by Philip Jackson in 1968, it was seen as a network of institutional values, rules and assumptions that were as important in shaping the character of the individual as well as the formal curriculum (15). In his Book Life in Classrooms he is quoted as saying; "It is certainly possible that many of our valedictorians and presidents of our honor societies owe their success as much to institutional conformity as to intellectual prowess" (15). However, most of the literature on the hidden curriculum is negative. Therefore, in this study critical thinking and self-perception as theories could be engaged to help the community make changes to improve the implementation of effective professionalism.

A formal curriculum was proposed that would address the deficiency in cognitive aspects of professionalism. It should be a blended curriculum, with a reflective group that would combine medical students, faculty and residents. Cruess and Cruess began by stating that professionalism must be taught with the main aim of adequately raising the awareness of the students so that they can reflect on what it is they have to do and be (16). This study suggested a well-structured mentorship program for small groups that would aid reflection on this issues that are similar to such groups like Relationship Centered Care initiative of Indiana University (17).

One of the ways of sustaining values in an organization is through regulation; the community of the practitioners recognizes this through the selfreflection on the unsatisfactory outcomes that they get and the disciplinary experiences in the hands of the regulator. The medical sociologists have long debated the place of self-regulation of organizations and how it helps keep the trust of the society in the individual professionals. It only works because they trust the organization to enforce regulatory measures 
to correct individuals who violate the values, norms and rules of the organization (18). The regulation, however, should be structured in such a way that it begins from medical school, rather than the current one which only begins once outside of medical school. This study indicates that regulation of practice and of learning may help in creating a situation where practitioners are forced to reflect on their actions or omissions.

While regulations exist, the way issues have been handled seems only to make the community think that professionalism is not taken seriously because the regulatory bodies appear to protect the doctors rather than look at the interests of the public. Furthermore, regulation, as practiced in other jurisdictions, not only includes penalizing unethical behaviors when they occur but also regular assessment of the clinicians' skills (20). The regulatory bodies play a critical role in ensuring those who are admitted are qualified, their teaching is up to date, and the final assessment is of quality (20). Improvement of the educational environment was suggested as one of the ways in which individuals could build an educational community.

Theinstitution that appreciates hard working members through non-cash or cash rewards, that organizes informal gatherings where members feel free to talk openly and play with each other fosters networks that go a long way in enabling professionalism to thrive. This was suggested in this study but was also shown in the literature on professionalism as well (21). The enabling environment may also require a specific designated teaching hospital as opposed to using a public hospital to teach. This is because a shared hospital engenders difficulties of lack of shared values. The student-to-faculty ratio is part of an enabling environment and therefore should be reduced to a number that can foster one faculty member to few students to enable that reflective activity (1).

Both teachers and students alike spoke of the need for an enabling environment regarding facilities for teaching and learning but also one where the focus is not only on academic grades. Some suggested forums where students interact with students as well as faculty so that they get to know one another outside the class rooms. It is crucial because the way the society socializes dictates what values are picked by the young for their personal frameworks $(1,12)$. The activeness of an educational community is crucial to the learning of professional values.
Practicing and teaching in a public hospital in a developing country has its limitations. There have been certain times when patients are not able to afford the care, and so there was a suggestion of universal insurance cover so that no one would miss care because of finance or lack of resources. This lack of resources, especially in the public hospitals, has been an excuse for neglecting the patients in this sector to go and practice in private hospitals where there are resources. It is also possible that if health care financing were to be structured in a way that everyone is catered for, the divide along social classes would be reduced. Additionally, it would bring resources to the hospital and ensure the presence of the faculty in the hospital, hence increase the interaction between patients, trainees and trainers. It can potentially increase the learning of values, as the senior doctors will be more likely to remain available to public patients rather than withdrawing to their private practices. Structured health care financing may also reduce the burden of pay on the government for salaries and shift it to health facilities. They would then be able to pay their staff and in the process, reduce the chances of industrial action to force the government to improve remuneration. Proper utilization of resources by reducing wastage and corruption was suggested to deal with poor resourcing in our context as well as better remuneration of the health care workers.

The reward system was also proposed as a way to motivate staff. This reward does not necessarily need to be financial and can be used as an incentive to both the students and the staff to increase and sustain professional behavior. Two practical ways have been suggested in the literature. First, national humanism in medicine awards given by the Association of American Medical Colleges (AAMC) and secondly, the Arnold P Gold Foundation and Health Foundation of New Jersey (21) giving points for promotion, the educational Relative Value Units (RVUs) for excellent role modeling (22).

This study had suggestions of further rewards like giving mortgages at cheaper rates, health insurance, research grants and scholarships that could provide further incentives to strengthen and foster professionalism. In the case of students, the reward could be by improving their assessment or by enlarging the areas to be assessed. Values need 
time and availability of the supervisor to observe and evaluate for them to grow and mature (12). The surgeons who are meant to be supervisors often hardly have time and are frequently not available in the ward to assess the student (23). When they do assess, they are likely not to be candid with students on their feedback (23). Some are not candid as a cover up for their absence and others for unawareness on how assessment in such areas should be performed. There is hence the need for faculty development in these areas (24). There may be a need for explicit grading of professionalism that has consequences, and it needs to be in practical areas (22).

The study also found that one of the problems is the increased number of students with no corresponding increase in the number of faculty or increase in the teaching facilities. This makes the environment congested and was suggested by some students as "not good for the patient and practitioners." The increased numbers also reduce interaction between supervisor and trainee. This may mean a reduction in the number of students to match the number of teachers or increase faculty as well as building a teaching hospital

\section{Conclusion}

This study demonstrates that the participants are aware of the deficiencies and are able to critically think through and offer solutions that are in tandem with transformational changes known elsewhere despite their challenges and weakness. These changes include building a reflective group and changing values among others.

\section{References}

1. Rabow MW, Remen RN, Parmelee DX, et al. Professional Formation: Extending Medicine's Lineage of Service into the Next Century. Acad Med J Assoc Am Med Coll. 2010;85(2):310-7.

2. Newton BW, Barber L, Clardy J, et al. Is There Hardening of the Heart During Medical School? Acad Med. 2008;83(3):244-9.

3. Borrell-Carrió F, Suchman AL, Epstein RM. The Biopsychosocial Model 25 Years Later: Principles, Practice, and Scientific Inquiry. Ann Fam Med. 2004;2(6):576-82.

4. Ojuka D, Olenja J, Eunbae Y, et al. Challenges in Practicing and Inculcating Professionalism in The University of Nairobi: A Mixed Methods
Study. Mededpublish [Internet]. 2015;6(4). Available From: Http://Www.Mededworld.Org/ Mededworld-Papers/Papers-Items/ChallengesIn-Practicing-And-Inculcating-Professio.Aspx

5. Lucheli I. Standard Digital News - Doctor Who Left Woman's Belly Open Deregistered [Internet]. Standard Digital News. [Cited 2016 ]. Available From: Http://Www.Standardmedia.Co.Ke/Mobile/ Article/2000085183/Doctor-Who-Left-Woman-SBelly-Open-Deregistered

6. Nation Team. Monday, March 23, 2015 Police Quiz MP In Rape Scandal Amid Public Fury. Daily Nation , Kenya. News. 2015;

7. Chapanis NP, Chapanis A. Cognitive Dissonance. Psychol Bull. 1964;61(1):1-22.

8. Bem DJ. Self-Perception: An Alternative Interpretation of Cognitive Dissonance Phenomena. Psychol Rev. 1967;74(3):183-200.

9. Jack M. Fostering Critical Reflection in Adulthood. San Francisco: Jossey-Bass; 1990.

10. Engeström Y. Expansive Learning at Work: Toward an Activity Theoretical Reconceptualization. J Educ Work. 2001;14(1):133-56.

11 Pellegrino ED. Toward a Reconstruction of Medical Morality. Am J Bioeth. 2006;6(2):65-71.

12. Duckett SJ. Health Workforce Design for the 21st Century. Aust Health Rev Publ Aust Hosp Assoc. 2005;29(2):201-10.

13. Langendyk V, Mason G, Wang S. How Do Medical Educators Design a Curriculum That Facilitates Student Learning About Professionalism? Int J Med Educ. 2016;7:32.

14. Jackson PW. Life in Classrooms [Internet]. Teachers College Press; Available From: Https://Books. Google.Com/Books?Hl=En\&Lr=\&Id=W46Gu6ww YsQC\&Oi=Fnd\&Pg=PR9\&Dq=Life+In+Classroom+ Jackson\&Ots=Qyxvyfy1 pa\&Sig=Cgrnqgysowjmsyz o 2 zj2 $\operatorname{lm} 1 \mathrm{tf} 2 \mathrm{o}$

15. Cruess SR, Cruess RL. Professionalism Must Be Taught. BMJ. 1997;315(7123):1674-77.

16. InuiTS, LitzelmanDK,Mossbarger DL.Transforming The Professional Culture of a Medical School. 2007 Available From: Https://Www.Acgme. Org/Portals/0/Pdfs/Symposium/Suchman_ Transforming $\% 20$ the $\% 20$ Professional $\% 20$ Culture\%20of\%20a\%20Medical\%20School.Pdf

17. Latham SR. Medical Professionalism. Mt Sinai J Med. 2002;69:363-9. 
18. Donaldson L. Good Doctors, Safer Patients: Proposals to Strengthen the System to Assure and Improve the Performance of Doctors and to Protect the Safety of Patients. Lond Dep Health. 2006;

19. Gold A, Gold S. Humanism in Medicine from the Perspective of The Arnold Gold Foundation: Challenges to Maintaining the Care in Health Care. J Child Neurol. 2006;21(6):546-9.
20. Shrank WH, Reed VA, Jernstedt GC. Fostering Professionalism in Medical Education. J Gen Intern Med. 2004;19(8):887-92.

21. Burack JH, Irby DM, Carline JD, Et Al. Teaching Compassion and Respect. J Gen Intern Med. 1999;14(1):49-55.

22. Richards BF, Wilking AP, Kirkland RT. A Four-Month Faculty Development Curriculum on Teaching and Learning. Acad Med. 1999;74(5):614-5. 